\title{
Life before and after residents: subjective reports on quality of life from urologists since inception of a new residency program
}

\author{
Gregory Roberts, MD; ; Paul Whelan, MD, FRCSC; ${ }^{\dagger}$ Anil Kapoor, MD, FRCSC ${ }^{\dagger}$
}

\begin{abstract}
Background: It is difficult to determine the effect of a residency program on the life of staff urologists. The objective of this study was to obtain subjective reports from urologists who have practiced before and after the implementation of a training program on how it affects their careers in 5 spheres: education, job-stress, free time, financial life and subjective quality of life.

Methods: We asked urologists from McMaster University to complete a questionnaire to quantify how their current experiences have changed compared to the pre-residency program era on a balanced 7 -point scale $(4=$ neutral).

Results: The response rate was 100\% (9/9). Eight of the 9 urologists $(89 \%)$ reported they would implement the program again if they could rewind the clock. Eight of 9 reported their overall career-related quality of life improved, with an average rating of 5.1 on the 7 -point scale. The quality of continuing education was the most positive ranking at 5.4 followed by job stress at 5.2 . The outcomes measured below 4 (neutral) were earning potential at 3.8 and ability to engage in pastimes at 3.4. Earning potential was clustered tightly around neutral, with 7 of the 9 respondents reporting no change. The largest standard deviation, corresponding to the most disagreement, was in their ability to engage in pastimes. Conclusion: Even with a mild decrease in earning potential and increased job stress, McMaster urologists feel their quality of life and continuing education have improved since the program's implementation; these urologists are almost uniformly happy they started a residency teaching program at their centre.
\end{abstract}

Cite as: Can Urol Assoc J 2011;5(2):103-6; D01:10.5489/cuaj.10091

\section{Résumé}

Contexte : Il est difficile de déterminer l'effet d'un programme de résidence sur la vie des urologues membres du personnel. L'objectif de notre étude était d'obtenir des rapports subjectifs d'urologues ayant pratiqué avant et après l'implantation d'un programme de formation sur la façon dont ce programme avait influé sur leur carrière dans 5 domaines : éducation, stress professionnel, temps libres, finances et qualité de vie subjective.

Méthodologie : Nous avons demandé à des urologues de I'Université McMaster de remplir un questionnaire pour quantifier sur une échelle équilibrée en 7 points ( $4=$ neutre) de quelle façon leurs expériences actuelles avaient changé par comparaison avec la période avant le programme de résidence.
Résultats : Le taux de réponse a été de $100 \%$ (9/9). H.uit des neuf urologues (89\%) ont signalé qu'ils remettraient en œuvre le programme s'ils pouvaient reculer dans le temps. Huit urologues sur neuf ont aussi indiqué que leur qualité de vie globale en lien avec leur carrière s'était améliorée; la cote moyenne accordée était de 5,1 sur l'échelle en 7 points. La qualité de la formation continue recevait la note la plus élevée, soit 5,4, suivie du stress professionnel à 5,2. Les domaines recevant une cote inférieure à 4 (neutre) étaient le potentiel de revenus $(3,8)$ et la capacité de vaquer à des activités de loisir. Le potentiel de revenus était coté très près de la note neutre; en effet, 7 des 9 répondants n'ont signalé aucun changement. L'écart type le plus large, correspondant au plus important désaccord, se situait au niveau de la capacité à vaquer à des activités de loisir.

Conclusion : Même avec une légère hausse dans le potentiel de revenus et un stress professionnel plus élevé, les urologues de I'Université McMaster croient que leur qualité de vie et leur formation continue se sont améliorées depuis l'implantation du programme; ces urologues sont heureux, de façon presque uniforme, d'avoir entrepris un programme de formation de niveau résidence à leur centre.

\section{Introduction}

Research has reported that staff physicians working in residency training programs are generally undercompensated for the hours that they spend in educational duties. ${ }^{1}$ Additionally, operating room time increases when attending surgeons and residents collaborate on cases. It is difficult, however, to assess the opportunity-cost to the attending surgeons overall, since residents unload many of the preoperative and postoperative patient care tasks, and provide the sometimes arduous task of on-call care. The McMaster University urology training program has the unique advantage of having staff that have lived and worked before and after the program's implementation, thus giving them rare insight into the urologists' career pre- and post-residency program.

The objective of this study was to obtain subjective reports from urologists who have practiced before and after the implementation of a training program and assess how the implementation affected their careers in 5 spheres: educational, job stress, free time, financial and subjective quality of life. 
Roberts et al.

\section{Methods}

A questionnaire was sent to all McMaster University urologists who have practiced before and after the residency program was implemented. Seven questions, formatted with a balanced positive and negative answer scheme (1-exceedingly lower, 4-neutral, 7-exceedingly higher) were answered by urologists who fit the inclusion criteria (current staff who had worked for at least 1 year before the residency program was initiated in 2003). The questions elicited subjective reports on the effects of the program on the staff urologists' job stress, continuing education, ability to engage in pastimes, earning potential, overall quality of life and, ultimately, if they would want to work at a centre with a residency program if they could do it over again. Results were then tabulated and analyzed using basic descriptive statistical methods.

\section{Results}

The response rate was $100 \%$ for all 9 urologists who fit the inclusion criteria. The average age was 53.5 (range 67-43) and the average years worked at McMaster was 19.6 (range 9-37). The results showed that 3 outcomes were rated on average by the group to be higher than neutral since the inception of the program: (1) quality of continuing education, (2) overall quality of life and (3) job stress (Fig. 1). These 3 measurements were positive in varied degrees on the scale, with the quality of continuing education rated most positively at 5.4 out of 7 . Job stress was second at 5.2 and overall quality of life at 5.1. On average, 2 of the outcomes were ranked below neutral: ability to engage in pastimes and earning potential. However, the perception of decreased earning potential due to resident teaching was very slight at $3.8 ; 7$ of the 9 respondents reported no change and 2 reported earning potential to be mildly lower. The ranking of the ability to engage in pastimes was the lowest at 3.4.

Finally and possibly most importantly, of the McMaster urologists who have worked before and after the residency program, 89\% (8/9) would start the residency program again if they had the chance.

Standard deviations were also computed to measure the degree of disagreement among respondents. The highest standard deviation was in the category "ability to engage in pastimes" with different urologists reporting that their capacity was substantially higher since the residents started, and others reporting it to be exceedingly lower. The lowest standard deviation was in the category of "change in earning potential" (Fig 2).

More specific financial information was elicited by asking respondents how many dollars they would estimate they gained or lost in $\$ 25000$ per-year increments. Results showed that a most respondents $(n=6)$ thought that their

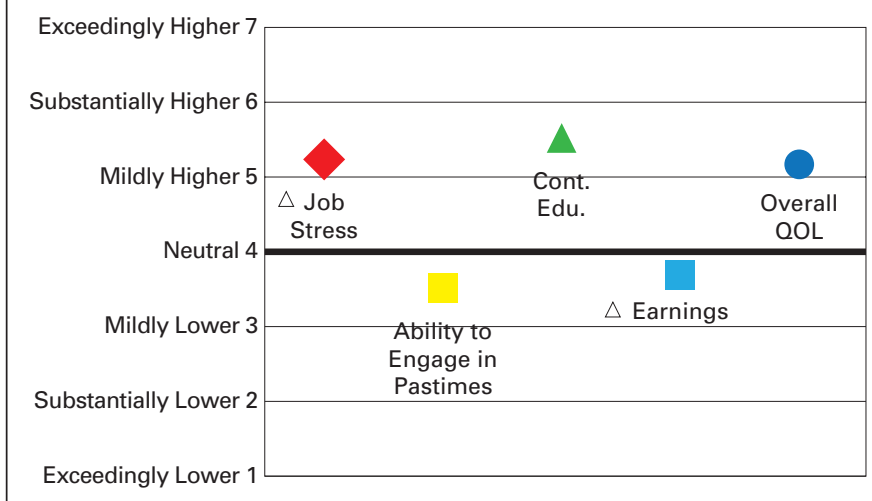

Fig. 1. Average ratings for the 5 outcomes.

income was not affected by the program. The other 3 respondents determined that they roughly lost between $\$ 25000$ to $\$ 50000$ per year, $\$ 50000$ to $\$ 75000$, and $\$ 75000$ to $\$ 100000$ per year, respectively (Fig 3).

After each multiple-choice question on the survey, participants were encouraged to comment or clarify their response. Although not every urologist commented after every question, there were a total of 23 unique comments. Of the 23 comments, 18 were deemed to be "positive" or pro-residency program and 5 were "negative" or contraresidency program.

\section{Discussion}

Although a relatively small sample size $(n=9)$, this number represents the largest possible sample group in Canada, considering that McMaster is the newest and only urology residency program to have staff who have previously worked in the same practice without a residency program and currently work in a Royal College teaching program. Because respondents worked in the same practice, the addition of residents functions as the independent or "treatment" variable in an otherwise (relatively) constant environment. These are the only urologists in the nation who have seen first-hand how a teaching program affects a urologist's career. There are 15 residents in the program ( 3 per year) and one fellow in minimally invasive surgery per year. The residents' rotations are site-based at 1 of the 3 sites (St. Joseph's Healthcare, Hamilton General and the University Hospital), rather than preceptor-based. There is at least 1 resident team at each site year-round, thus each of the 9 urologists surveyed has steady interaction with the residents in the operating room and the clinics. With this in mind, this study may help 2 types of groups: (1) urologists who are contemplating initiating residency programs at their institutions and (2) individuals who are contemplating a career shift either into or away from academic practice.

The most important conclusion of the study is that a vast 


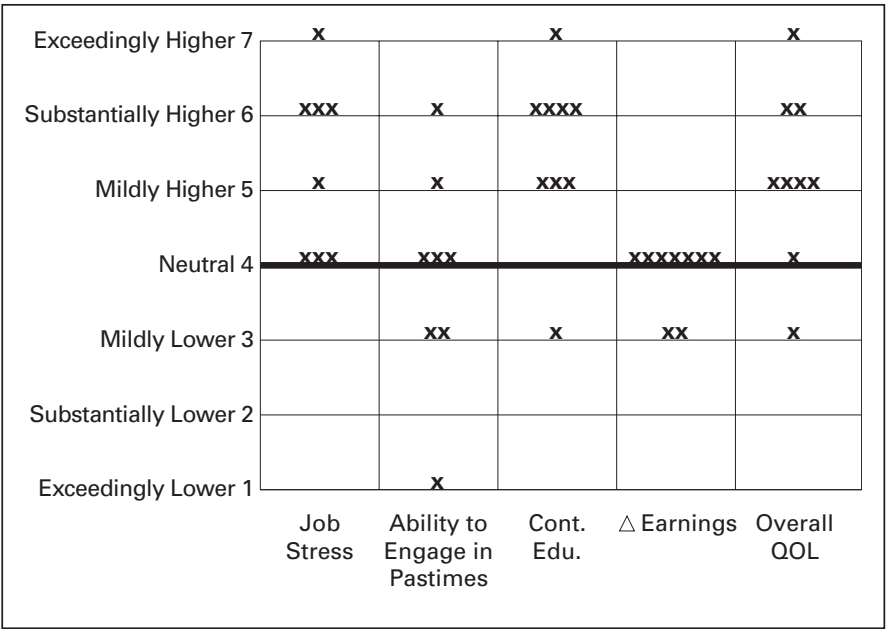

Fig. 2. Actual responses to the 5 outcomes and standard deviations.

majority of respondents (8 out of 9) are happy with the change in their career since the implementation of the training program and would be happy to do it again if they could rewind the clock.

The most uniformly agreed upon statement was that continuing education improved with a training program. This is somewhat intuitive as all residency programs have mandatory research components, journal clubs and teaching rounds. As young physicians are constantly looking to more experienced staff to answer questions with the latest evidence-based answers, it no surprise to find that preceptors are, as one staff man said, "more inclined to keep up on the literature." Improved quality of continuing education seemed to a be a common theme emphasized by such comments as: "Rounds and journal clubs are at a much higher level" and "I think we have also learned to be more critical of data and learned to critically appraise papers."

It is obvious that as physicians keep up-to-date on medical advances and literature, patient care will naturally improve. Additionally, feedback from this study seems to infer that improved continuing education also results in happier surgeons. Being a preceptor "forces you to learn about the latest techniques to be able to teach them;" this challenges staff on intellectual and technical levels and fosters a dynamic and stimulating environment. As decreased job satisfaction and psychological distress are cited as correlated to perceived job monotony in other vocations, it follows that replacing older practices with new, evidence-based techniques every few years would keep surgeons invigorated and fend off burnout. One urologist summarizes this point nicely by stating. "[The program] has helped me maintain and renew my interest in the specialty."

Of the most interesting results of the study were the financial perceptions. A commonly held belief is that residents extend operating time. This perception has been substantiated in general surgery by Babineau and colleagues. ${ }^{2}$ They

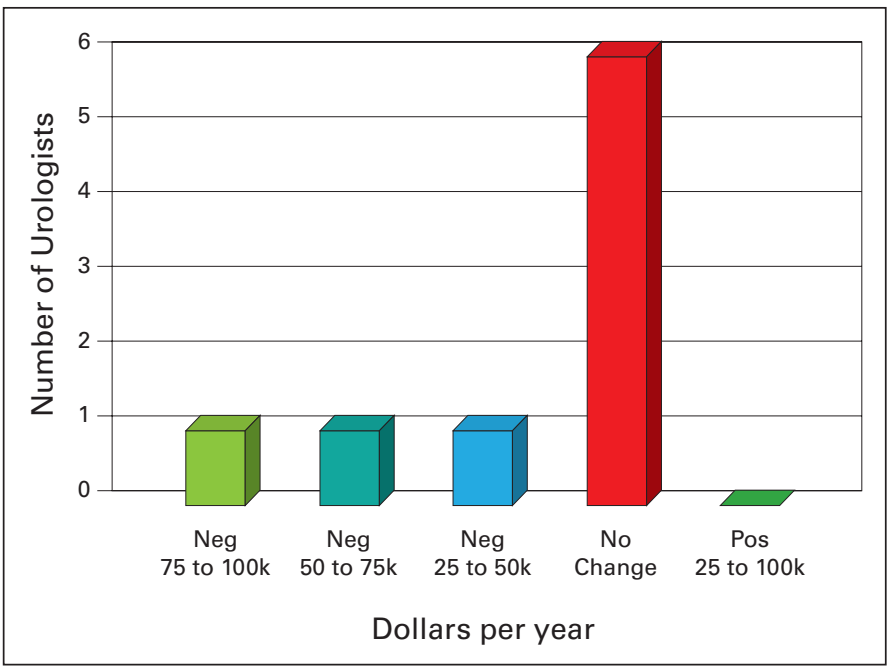

Fig. 3. Perceived change in earnings post-training program.

noted that skin-to-skin time increased by an average of as little as 8 minutes per resident-assisted hernia repair and as much as 60 minutes for partial colectomies. A similar anecdotal report from 1 urologist reported that he now books his transurethral resections of the prostate for 1.5 hours as opposed to 1 hour. However, the results of this small survey show that these increases in operative time have not translated into proportionate loss of income. Indeed, most respondents felt that the training program did not substantially affect finances; 7 respondents reported no change in their potential earnings. This is a testament to residents' ability to make other aspects of a urology practice more efficient. Staff urologists may offload much of non-clinical duties (such as dictations and paperwork) to residents thereby freeing up more time to engage in clinical and academic activities. ${ }^{3}$ Therefore, residents may serve to shorten office wait times and subsequently increase patient access. Hamilton urologists are on a fee-for-service payment protocol, and not a salary or other alternative payment program. As such, we can apply the results with more confidence to a similar payment program. ${ }^{4}$

Other worthy secondary outcomes include a perceived increase in job stress with the new program; this conclusion is not difficult to understand given the increased responsibility and liability assumed by staff when relatively young and untrained surgeons act on behalf of their preceptor (often in life-and-death situations).

Although the average score of "ability to engage in pastimes" is lower than neutral at 3.4, there was a significant outlier. One urologist stated that his ability to engage in pastimes was a 1 or "exceedingly lower." Without this outlier (who incidentally was the same respondent not in favour of the program as a whole), the average would have fell in the mildly higher region. This highlights the main weakness of the study — small sample size. With only 9 data points, 1 
Roberts et al.

outlier can significantly affect the average. Consequently, it is difficult to make a conclusion regarding this variable. However, the following comment provides a good representation of the group perception: "The benefits of more free time slightly outweigh stress and loss of income."

Lastly, overall quality of life was almost uniformly perceived as better post-residency program (again, only 1 outlier). This is also a powerful attestation to the positive nature of working in a teaching program. The terminology of "quality of life" is purposely vague and respondents could have interpreted this any way they saw fit. While 1 respondent reported that "my life is more satisfying and I feel privileged to pass to our residents all I have learned during my career," another respondent found that he felt pride in "watching students turn into surgeons" and yet another found that "more free time on call" was a major determination to his increased overall quality of life. The perception of increased quality of life is unique to each respondent. Whether quality of life improved because of continuing education, more free time, satisfaction of teaching or something not quantified in this survey, it serves as an effective and excellent summarizing statistic.

The limitations of this study include the subjective nature of the responses (i.e., one person's "mildly lower" is another's "neutral" depending on perspective). Other limitations include sample size and the inherent recall bias, given that 7 years had lapsed from the "before residents" era, which undoubtedly affected perceptions to some extent.

It should also be noted that there were some concurrent changes that may have influenced the urology group over the time period. Since the program started there has been an influx of tertiary and quaternary referrals as the centre began to take a role as the academic centre for the HamiltonNiagara Local Health Integration Network (LHIN). Due to the new program and the increased clinical volume, 6 new faculty members have been recruited. The consensus is that the increase in volume and increase in manpower have balanced nicely and there has not been any negative effect of this growth on income or quality of the sample population.

Future studies would ideally branch out to include larger sample populations, including other surgical and non-surgical specialties to compare the subjective effects of a training program in different fields. It would also be worthwhile to administer the same survey to other new urology programs in United States and Europe to increase the sample size and to determine if results are area-dependent.

\section{Conclusion}

Urologists in Hamilton, Ontario who have worked in a practice with and without resident teaching responsibilities agree that implementing a residency program has increased their quality of life; they do not regret starting the program. While the perception of the quality of continuing education has increased, so has job stress. Potential earnings were reported on average to decrease mildly, with 6 of 9 urologists claiming no annual change in earning since the program started.

*Department of Urology, Queens University, Kingston, ON; †Division of Urology, McMaster University, Hamilton, ON

Competing interests: None declared.

This paper has been peer-reviewed.

\section{References}

1. Shea S, Nickerson KG, Tenenbaum J, et al. Compensation to a Department of Medicine and its faculty members for the teaching of medical students and house staff. N Engl J Med 1996;334:162-7.

2. Babineau TJ, Becker J, Gibbons G, et al. The "cost" of operative training for surgical residents. Arch Surg 2004; 139:366-70.

3. Bridges M, Diamond DL. The financial impact of teaching surgical residents in the operating room. Am I Surg 1999;177:28-32.

4. Melamed S, Ben-Avi I, Luz J, et al. Objective and subjective work monotony: effects on job satisfaction, psychological distress, and absenteeism in blue-collar workers. J Appl Psychol 1995;80:538.

Correspondence: Dr. Anil Kapoor, Program Director, Division of Urology, McMaster University, 1280 Main St. West, Hamilton, ON L8S 4L8; akapoor@mcmaster.ca 